\title{
Potential of liraglutide in the treatment of patients with type 2 diabetes
}

\section{Carolyn F Deacon}

Department of Biomedical Sciences, Panum Institute, DK-2200

Copenhagen N, Denmark
Correspondence: Carolyn F Deacon Department of Biomedical Sciences, Panum Institute, Blegdamsvej 3, DK-2200 Copenhagen N, Denmark

Tel +453532 7523

Fax +45 35327537

Email deacon@mfi.ku.dk

\begin{abstract}
Liraglutide is a long-acting analog of GLP-1, being developed by Novo Nordisk and currently undergoing regulatory review for the treatment of type 2 diabetes. Upon injection, liraglutide binds non-covalently to albumin, giving it a pharmacokinetic profile suitable for oncedaily administration. In clinical trials of up to 1 year duration, liraglutide has been demonstrated to have beneficial effects on islet cell function, leading to improvements in glycemic control. Both fasting and postprandial glucose concentrations are lowered, and are associated with lasting reductions in HbA1c levels. Liraglutide is effective as monotherapy and in combination therapy with oral antidiabetic drugs, and reduces $\mathrm{HbA1}$ c by up to $\sim 1.5 \%$ from baseline $(8.2 \%-8.4 \%)$. Because of the glucose-dependency of its action, there is a low incidence of hypoglycemia. Liraglutide is associated with body weight loss, and reductions in systolic blood pressure have been observed throughout the clinical trials. The most common adverse events reported with liraglutide are gastrointestinal (nausea, vomiting and diarrhea). These tend to be most pronounced during the initial period of therapy and decline with time. Further clinical experience with liraglutide will reveal its long-term durability, safety and efficacy.
\end{abstract}

Keywords: liraglutide, GLP-1, incretin mimetic, type 2 diabetes

\section{Introduction}

Type 2 diabetes mellitus (T2DM) is a progressive disease, characterized by both insulin resistance and declining $\beta$-cell function which lead to impaired glucose-induced insulin secretion. Once insulin secretion can no longer compensate for the insulin resistance, hyperglycemia ensues, and with it, the development of micro- and macrovascular diabetic complications and associated increases in morbidity and mortality. Current treatment algorithms advocate the early use of metformin, together with lifestyle interventions (dietary modification, increased physical activity, weight loss) to control the hyperglycemia. ${ }^{1}$ However, for the majority of patients, this is insufficient, and most progress to require the use of several agents including insulin. Unfortunately, even with this approach, several long-term clinical trials (eg, United Kingdom Prospective Diabetes Study (UKPDS); A Diabetes Outcome Progression Trial (ADOPT)) have demonstrated that $\mathrm{HbA} 1 \mathrm{c}$ levels continue to rise over time, ${ }^{2-4}$ underscoring the need for new and more efficacious agents which not only target treatment, but also prevention of the disease, its progression and its associated complications.

One new approach is based upon the actions of the intestinal hormone glucagon-like peptide-1 (GLP-1). GLP-1, together with glucose-dependent insulinotropic polypeptide (GIP), is an incretin hormone which enhances meal-induced insulin secretion, while also having a number of other actions considered desirable in an anti-diabetic agent (Table 1). ${ }^{5-7}$ Thus, GLP-1 stimulates all steps in insulin biosynthesis and secretion, and has beneficial effects on both $\beta$-cell function and survival. It reduces excessive hepatic glucose production by suppressing glucagon secretion, it delays gastric emptying, leading to lower postprandial glucose excursions, and it has central effects to reduce appetite 
Table I Actions of GLP-I

\begin{tabular}{ll}
\hline Type 2 diabetic phenotype & Actions of GLP-I \\
\hline Impaired $\beta$-cell function & Increases insulin secretion (glucose-dependent) and biosynthesis \\
& Improves $\beta$-cell function (glucose sensitivity, proinsulin:insulin ratio, HOMA- $\beta$ ) \\
& Upregulates other genes essential for $\beta$-cell function (eg, GLUT 2, glucokinase) \\
& Increases $\beta$-cell proliferation/differentiation ${ }^{\mathrm{a}}$ \\
& Reduces $\beta$-cell apoptosis \\
Reduced $\beta$-cell mass & Increases $\beta$-cell mass \\
& Reduces glucagon secretion (glucose-dependent) \\
Glucagon hypersecretion & Delays gastric emptying \\
Postprandial hyperglycemia & Delays gastric emptying, increases satiety, reduces appetite $\rightarrow$ decreased food intake and body weight \\
Overeating, obesity & Beneficial cardiovascular effects \\
Macrovascular complications & Improvements in insulin sensitivity \\
Insulin resistance &
\end{tabular}

Note: For a review, see $\mathrm{s}^{5-7}$

aEffects shown only in preclinical in vitro and animal studies.

${ }^{\mathrm{b}}$ Action which is likely to be secondary to improvements in metabolism rather than a direct effect of GLP-I.

and food intake, resulting in body weight loss, while more recent studies point to beneficial cardiovascular effects..$^{5-7}$ GIP has similar effects to GLP- 1 on the $\beta$-cells, but it does not inhibit glucagon secretion, and has only minimal effects on gastric emptying. Appetite is unaffected by GIP, but GIP has been implicated in the control of lipid metabolism, and may have a role in the regulation of bone remodeling. ${ }^{5}$

When given as an intravenous infusion, GLP-1 has been demonstrated to normalize both fasting and postprandial plasma glucose concentrations in patients with $\mathrm{T} 2 \mathrm{DM},{ }^{8,9}$ whilst continuous subcutaneous administration greatly improves metabolic control, lowering glucose profiles and HbA1c levels, improving $\beta$-cell function and reducing body weight over a 6 -week period. ${ }^{10}$ However, GLP-1 is extensively degraded in vivo, ${ }^{11}$ primarily by the enzyme dipeptidyl peptidase-4 (DPP-4), with such rapidity that its apparent half-life is only in the order of 1 to 2 minutes and its metabolic clearance rate exceeds the cardiac output by 2 - to 3 -fold, ${ }^{12,13}$ with the resultant metabolite lacking insulinotropic effects. Other enzymes, such as netutral endopeptidase 24.11 (NEP) are also able to cleave GLP-1 in vivo, ${ }^{14}$ while furthermore, the peptide is efficiently cleared by the kidneys at a rate which exceeds the glomerular filtration rate. ${ }^{15}$ Together, these factors mean that the native peptide cannot be used therapeutically, and there has, therefore, been much effort placed upon identifying metabolically stable analogs or derivatives of GLP-1 which are not subject to the same enzymatic degradation or renal clearance. Although a simple substitution of the penultimate N-terminal amino acid prevents degradation by DPP-4, these analogs are still rapidly cleared by the kidneys. ${ }^{16}$ In the search for more stable analogs, two distinct groups of compounds have attracted much interest: (i) compounds based upon mammalian GLP-1, which have been modified to facilitate binding to plasma proteins, such as albumin, to protract their action and (ii) compounds which are based upon the sequence of exendin-4, a naturally occurring peptide originally isolated from the saliva of the Gila monster (Heloderma suspectum), which shares 53\% homology with GLP-1 and is a full agonist at the GLP-1 receptor. ${ }^{17}$ Exendin-4 is resistant to DPP-4, and is cleared from the plasma exclusively by glomerular filtration. ${ }^{15}$

This article focuses upon liraglutide, being developed by Novo Nordisk, which is based upon mammalian GLP-1. Novo Nordisk submitted a new drug application (NDA) to the food and drug administration (FDA) in the United States and a marketing authorization application to the European Medicines Agency (EMEA) in Europe in May 2008. An NDA was submitted to the Japanese regulatory authorities in July 2008.

\section{Liraglutide Chemistry and pharmacokinetics}

Liraglutide ( $\gamma$-L-glutamoyl(N- $\alpha$-hexadecanoyl)-Lys, ${ }^{26}$ $\mathrm{Arg}^{34}$-GLP-1(7-37)) is an acylated derivative of mammalian GLP-1, sharing 97\% sequence homology with the native peptide (Figure 1). It is based upon the sequence of GLP-1 (7-37), with the addition of a glutamic acid residue at position 26, allowing attachment of a palmitoyl group, and a substitution (arginine instead of lysine) at position $34 .{ }^{18}$ In vitro studies show that, despite the modifications, liraglutide retains affinity for the GLP-1 receptor. ${ }^{18}$ The palmitoyl group facilitates non-covalent binding to albumin after injection, 


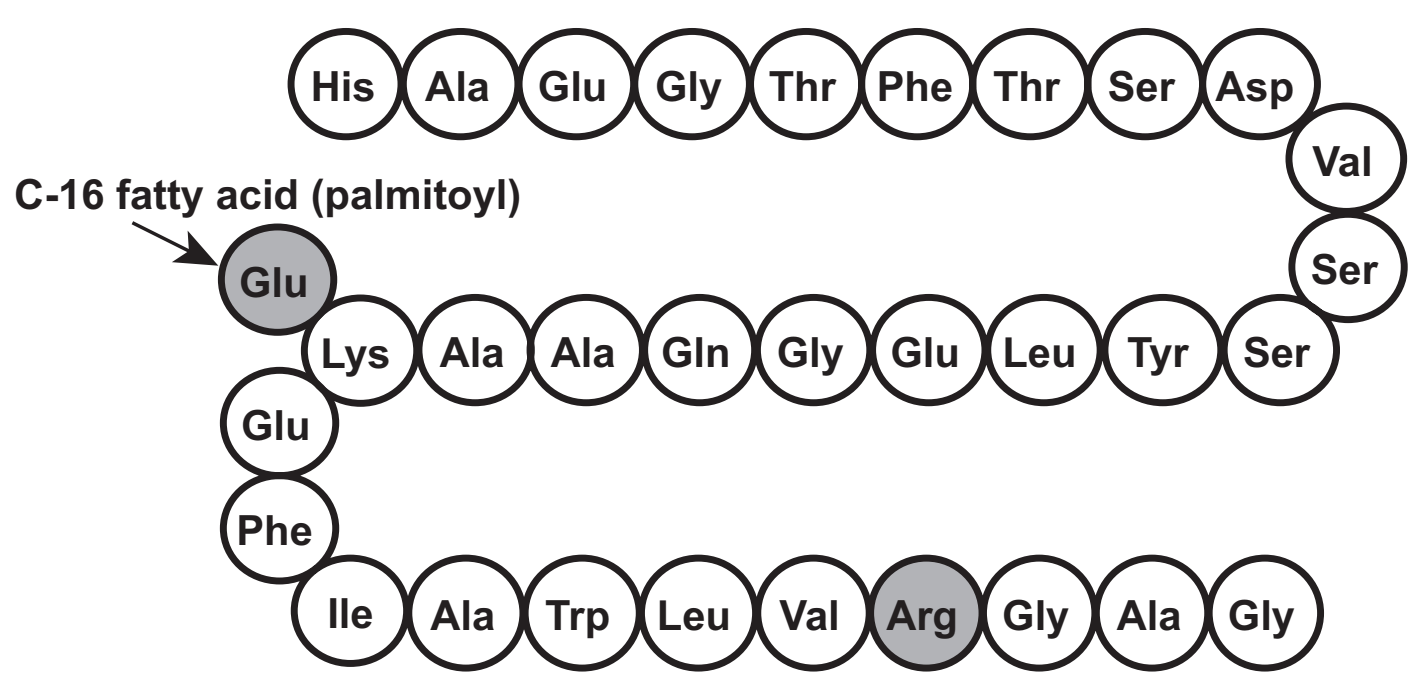

Figure I Primary structure of liraglutide (shaded residues indicate differences from mammalian GLP-I).

whereby the peptide escapes glomerular filtration. Together with self-association, this results in a pharmacokinetic profile with slow absorption ( $\mathrm{T}_{\max }$ of $\sim 10-14$ hours) and a long half-life of around $12 \frac{1}{2}$ hours after subcutaneous injection, ${ }^{19}$ making it suitable for once-daily administration. Although liraglutide is metabolized slowly in vitro by DPP-4 and $\mathrm{NEP},{ }^{20}$ in vivo, the albumin binding is likely to hinder enzymatic access to the molecule, while furthermore, acting as a buffer reservoir, which contributes to the long half-life of the compound. Thus, in vivo, the majority of liraglutide $(>89 \%)$ is found in the plasma as the intact molecule. No intact liraglutide and only low levels of metabolites were detected in the urine or feces, suggesting that liraglutide is probably degraded at a very slow rate into small peptides, amino acids and fatty acid fragments which are subsequently eliminated via the liver and kidney, or recycled into new endogenous proteins and lipids. ${ }^{20}$ Perhaps because of this, a pharmacokinetic study indicated that dose-adjustment was unnecessary in subjects with renal impairment. ${ }^{21}$ When adjusted for body weight, age or gender has no effect upon the pharmacokinetics of liraglutide (1 mg) in healthy subjects; ${ }^{22}$ dose-dependent increases in exposure are seen with doses up to $12.5 \mu \mathrm{g} / \mathrm{kg}$, but the $\mathrm{t}^{1 / 2}$ remains constant. ${ }^{19}$ These findings were subsequently reproduced using doses up to $25 \mu \mathrm{g} / \mathrm{kg}$ in healthy Japanese subjects. ${ }^{23}$

\section{Early clinical studies}

Early clinical studies with liraglutide showed that a single subcutaneous injection $(10 \mu \mathrm{g} / \mathrm{kg})$ reduced both fasting and postprandial blood glucose concentration in subjects with T2DM. ${ }^{24}$ Subsequently, treatment with liraglutide $(6 \mu \mathrm{g} / \mathrm{kg})$ for 1 week improved both $\alpha$ - and $\beta$-cell function, resulting in improved 24-hour glycemic control in patients with T2DM . ${ }^{25}$

Eight weeks of treatment with liraglutide $(0.6 \mathrm{mg})$ in obese subjects with T2DM (baseline HbA1c 7.5\%) significantly reduced glycemia $(-0.33 \%$ for liraglutide, $+0.47 \%$ for placebo), but had no significant effect on body weight $\left(-0.7 \mathrm{~kg}\right.$ for liraglutide, $-0.9 \mathrm{~kg}$ for placebo). In this study, ${ }^{26}$ body composition was assessed, showing that liraglutide was associated with small (non-significant) trends towards a reduction in total fat mass and an increase in lean body mass. Overall 24-hour energy expenditure was not affected by liraglutide treatment. ${ }^{26}$

In a 12-week randomized, placebo-controlled doseresponse study (baseline HbA1c 7.6\%), monotherapy with liraglutide in doses of 0.045 up to $0.75 \mathrm{mg}$ led to reductions in $\mathrm{HbA1c}$ with all but the lowest dose. ${ }^{27}$ Compared with placebo, the two highest doses of liraglutide $(0.60$ and $0.75 \mathrm{mg})$ resulted in $\mathrm{HbA} 1 \mathrm{c}$ changes of $-0.70 \%$ and $-0.75 \%$ after 12 weeks, which were similar to the reduction obtained with the active comparator (glimepiride, $-0.74 \%$ ). Fasting plasma glucose (FPG) levels also decreased, with the maximal effect being observed after the first week of treatment and maintained over the 12-week study period. As with the effect on $\mathrm{HbA1c}$, the effect of the two highest doses of liraglutide was comparable to that of glimepiride. In this study, body weight did not increase, but there was no clear dose-response relationship; a significant reduction $(-1.2 \mathrm{~kg})$ was obtained with the $0.45 \mathrm{mg}$ dose but not with the two highest liraglutide doses. $^{27}$

In another dose-response study, patients with T2DM discontinued their usual oral anti-diabetic drug (OAD) and 
entered a metformin run-in period (500 mg bid for 2 weeks, $1000 \mathrm{mg}$ bid for 2 weeks) before being randomized to liraglutide monotherapy ( 0.045 up to $0.75 \mathrm{mg}$ ) or continuing metformin (1000 mg bid) for 12 weeks. ${ }^{28}$ The two lowest doses of liraglutide $(0.045$ and $0.225 \mathrm{mg})$ were insufficient to maintain the glycemic control obtained with metformin (baseline HbA1c 7\%), but the three highest doses $(0.45,0.6$ and $0.75 \mathrm{mg}$ ) were comparable to metformin (change in $\mathrm{HbA} 1 \mathrm{c},+0.22 \%,+0.16 \%$ and $+0.30 \%$, respectively vs $+0.09 \%$ for metformin at week 12$).{ }^{28}$ Relative to baseline, all liraglutide doses led to weight loss over the 12 weeks, which was, however, not significantly different compared with metformin, and again, no clear dose-response relationship was apparent. All treatment groups except for the lowest liraglutide dose $(0.045 \mathrm{mg})$ showed a decrease in total body mass and total fat mass which was comparable to that induced by metformin alone. ${ }^{28}$ Mathematical modeling of the results, however, suggested that the dose range in this trial was likely to have been sub-optimal in terms of $\mathrm{HbAlc}$ reduction.

Collectively, therefore, these results indicated that higher doses of liraglutide may have greater efficacy, and subsequently, Nauck et $\mathrm{al}^{29}$ investigated the effect of higher doses of liraglutide (titrated weekly in $0.5 \mathrm{mg}$ increments from 0.5 to $2.0 \mathrm{mg}$ ) in a randomized double-blinded placebocontrolled protocol in patients with poorly controlled diabetes (HbAlc $\sim 9.4 \%$ ). Subjects on metformin monotherapy (1000 $\mathrm{mg}$ bid) were randomized to receive continuing metformin monotherapy, metformin plus the addition of liraglutide, or liraglutide monotherapy. In addition, an openlabel group received metformin plus glimepiride. FPG levels remained unchanged on metformin monotherapy, whereas they were reduced by $1.4 \mathrm{mmol} / \mathrm{L}$ in the subjects switched from metformin to liraglutide monotherapy. When compared to metformin monotherapy, the addition of liraglutide resulted in a further reduction of $3.9 \mathrm{mmol} / \mathrm{L}$ after 5 weeks of treatment, accompanied by a $0.8 \%$ reduction in $\mathrm{HbA} 1 \mathrm{c}$ (baseline HbAlc $9.4 \%$ ). Furthermore, the combination of metformin plus liraglutide gave a greater reduction in FPG levels compared with metformin plus glimeperide (between group difference of $1.4 \mathrm{mmol} / \mathrm{L}$ in favor of liraglutide). In terms of body weight, both liraglutide as monotherapy and in combination with metformin led to body weight reductions $(-2.1$ and $-2.2 \mathrm{~kg}$ from baseline, respectively) compared with metformin $(-1.7 \mathrm{~kg})$ and metformin plus glimepiride $(+0.8 \mathrm{~kg})$ after 5 weeks of treatment. Treatment effects on body weight and fasting glucose remained largely unchanged when patients experiencing nausea for more than 1 week were excluded from the analysis. ${ }^{29}$
In a 14-week study $(\mathrm{n}=165)$ investigating the efficacy of liraglutide monotherapy, HbA1c was dose-dependently reduced from baseline $(\sim 8.3 \%)$ by $0.98 \%, 1.40 \%$ and $1.45 \%$ for liraglutide doses of $0.65,1.25$ and $1.90 \mathrm{mg}$, respectively, compared with an increase of $+0.29 \%$ for placebo, with $46 \%$ of patients reaching the $\mathrm{HbAlc}$ goal of $<7 \%$ (compared to $5 \%$ on placebo). ${ }^{30}$ There were dose-related reductions in FPG (of between 2.7 and $3.4 \mathrm{mmol} / \mathrm{L}$ ), and postprandial glucose was also significantly reduced by liraglutide. Body weight fell in all liraglutide groups (by up to $3.0 \mathrm{~kg}$ for the $1.9 \mathrm{mg}$ dose).

In Japanese subjects with T2DM ( $\mathrm{n}=226$, baseline $\mathrm{HbA} 1 \mathrm{c}$ $8.3 \%)$, liraglutide $(0.1-0.9 \mathrm{mg})$ dose-dependently reduced $\mathrm{HbA1c}$ levels by 0.79 up to $1.85 \%$ relative to placebo treatment by week 14 , with $75 \%$ and $57 \%$ of subjects reaching target $\mathrm{HbA} 1 \mathrm{c}$ levels of $<7 \%$ and $<6.5 \%$, respectively, with the highest dose (vs 9 and $2 \%$, respectively, of subjects on placebo). ${ }^{31}$ Notably, in this study the HbA1c-lowering effect appeared to plateau at a dose of $0.9 \mathrm{mg}$, whereas in Caucasians, doses up to $1.9 \mathrm{mg}$ are required for maximal efficacy. ${ }^{30}$ This is most likely explained by the different nature of T2DM in Japanese diabetes, where $\beta$-cell dysfunction appears to play a greater role than insulin resistance. ${ }^{32}$ There were also dosedependent reductions in FPG (by up to $2.5 \mathrm{mmol} / \mathrm{L}$ relative to placebo) and postprandial glucose. ${ }^{31}$ In this study in lean subjects (weight $\sim 63 \mathrm{~kg}$, BMI $\sim 24 \mathrm{~kg} / \mathrm{m}^{2}$ ), body weight remained relatively stable (changes ranging from +0.1 to $-0.5 \mathrm{~kg}$ with liraglutide, vs $-1.0 \mathrm{~kg}$ with placebo). ${ }^{31}$

\section{Liraglutide effect and action in diabetes (LEAD) studies}

The LEAD program comprises six randomized, controlled, double-blind phase 3 studies in patients with inadequately controlled T2DM, designed to investigate the efficacy of liraglitide as monotherapy or as combination therapy with one or two OADs (Table 2). In all the trials, the liraglutide dose was initiated at $0.6 \mathrm{mg} /$ day for 1 week and titrated by weekly increments of $0.6 \mathrm{mg}$ to the final dose. Most of the LEAD studies included an active comparator.

LEAD-1 is a 26-week placebo-controlled study in 1041 patients with T2DM on background glimepiride ( $2-4 \mathrm{mg} /$ day) therapy (baseline $\mathrm{HbA} 1 \mathrm{c} \sim 8.4 \%$ ), designed to compare the effects of using liraglutide (0.6, 1.2 or $1.8 \mathrm{mg}$ once daily) or rosiglitazone (4 mg/day) as add-on therapy to sulfonylurea; preliminary results were presented at the annual meetings of the ADA and EASD. ${ }^{33,34}$ In this study, the addition of liraglutide or rosiglitazone gave additional reductions in $\mathrm{HbA} 1 \mathrm{c}$ compared to placebo, where $\mathrm{HbA1c}$ levels increased by $0.23 \%$ from baseline. Addition of rosiglitazone or the lowest 


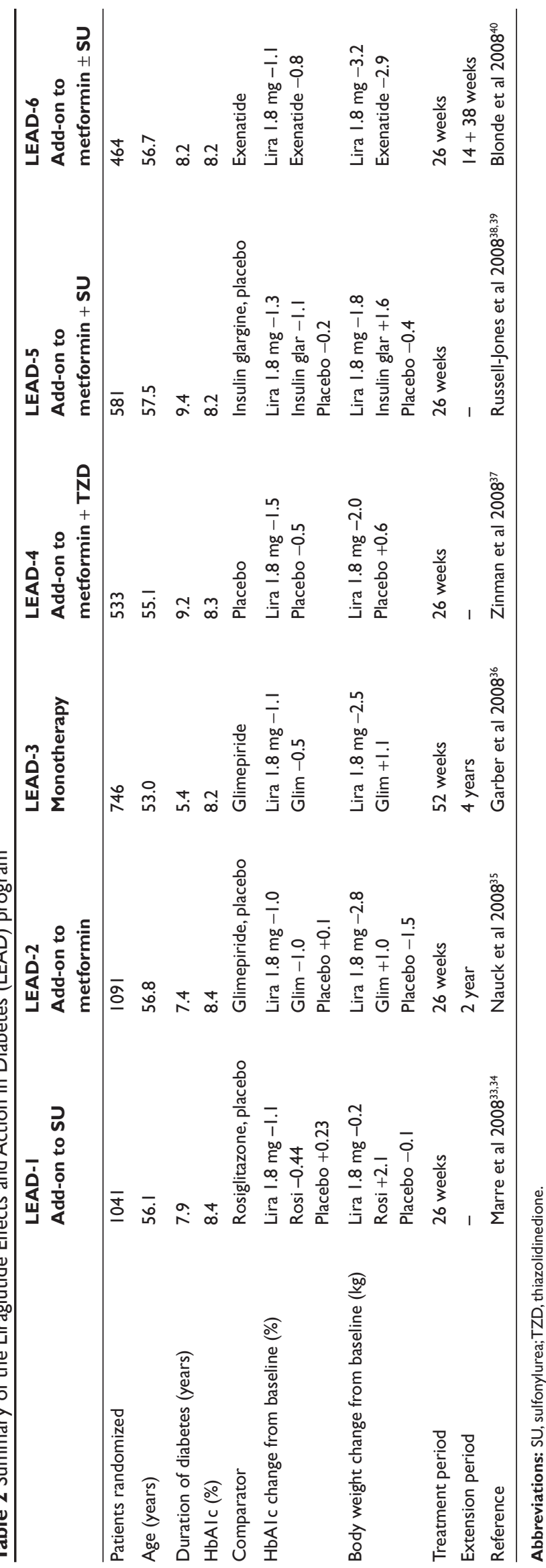

liraglutide dose $(0.6 \mathrm{mg})$ lowered $\mathrm{HbA} 1 \mathrm{c}$ to a similar extent $(-0.44 \%$ and $-0.60 \%$, respectively), whereas the two highest liraglutide doses were comparable and gave significantly greater reductions $(-1.08 \%$ and $-1.13 \%$, respectively). At week $26,42 \%$ of patients receiving $1.8 \mathrm{mg}$ liraglutide reached the ADA recommended target of $\mathrm{HbA} 1 \mathrm{c}$ of $<7 \%$, with $21 \%$ reaching $<6.5 \%$. FPG was reduced by both liraglutide and rosiglitazone combinations, compared to placebo, but with no significant differences between the active treatments arms (reductions of -0.7 to $-1.6 \mathrm{mmol} / \mathrm{L}$ ). Whereas the rosiglitazone combination resulted in a significant weight gain of $2.1 \mathrm{~kg}$ by week 26 , in this study liraglutide had no major effect on weight compared with placebo $(+0.7$, +0.3 and $-0.2 \mathrm{~kg}$ for $0.6,1.2$ and $1.8 \mathrm{mg}$ liraglutide; $-0.1 \mathrm{~kg}$ for placebo). ${ }^{33,34}$

In LEAD-2, the effect of liraglutide (0.6, 1.2 or $1.8 \mathrm{mg}$ once daily) was examined in 1091 patients with T2DM (baseline HbA1c 8.4\%) on background metformin (1 g twice daily) therapy in a placebo-controlled trial with glimepiride $\left(4 \mathrm{mg} /\right.$ day) as an active comparator. ${ }^{35}$ This was a 26 -week study, with an on-going 2-year continuation phase. Compared to placebo treatment, the addition of liraglutide to metformin significantly reduced $\mathrm{HbA} 1 \mathrm{c}$ (change from baseline, $-0.7 \%$, $-1.0 \%$ and $-1.0 \%$ for $0.6,1.2$ and $1.8 \mathrm{mg}$ liraglutide, respectively vs $+0.1 \%$ for placebo), with the two highest doses of liraglutide demonstrating non-inferiority to glimepiride added to metformin (-1.0\%). In the $1.8 \mathrm{mg}$ liraglutide group, $42 \%$ of patients reached target $\mathrm{HbA} 1 \mathrm{c}$ of $<7 \%$, comparable to glimepiride (36\%), but significantly more than in the placebo group (11\%), and $24 \%$ attained an $\mathrm{HbA} 1 \mathrm{c}$ of $<6.5 \%$ (compared to $22 \%$ on glimepiride and only $4 \%$ on placebo). FPG was significantly reduced by all active treatment combinations to a similar extent $(-1.1$ to $-1.7 \mathrm{mmol} / \mathrm{L}$ vs $+0.4 \mathrm{mmol} / \mathrm{L}$ for placebo). Postprandial glucose values in all liraglutide groups were reduced compared to placebo, with the 1.2 and $1.8 \mathrm{mg}$ doses $(-2.3$ and $-2.6 \mathrm{mmol} / \mathrm{L}$, respectively) giving similar results to glimepiride $(-2.5 \mathrm{mmol} / \mathrm{L})$. Addition of liraglutide produced dose-dependent decreases in body weight ( -1.8 to $-2.8 \mathrm{~kg}$ at week 26$)$, which were significantly greater than in the placebo group $(-1.5 \mathrm{~kg})$ for the two highest doses, and which contrasted with a $1.0 \mathrm{~kg}$ weight gain with glimepiride. ${ }^{35}$

The LEAD-3 study is a head-to-head comparison of monotherapy with liraglutide (1.2 or $1.8 \mathrm{mg}$ once daily) or glimepiride ( $8 \mathrm{mg} /$ day) in 746 patients with T2DM (baseline HbA1c $8.2 \%$ ) over 52 weeks, ${ }^{36}$ with a further on-going 4-year extension period. Any previous treatment (OAD monotherapy of up to half the maximal dose) was discontinued 
at randomization. At 1 year, $\mathrm{HbA} 1 \mathrm{c}$ had decreased from baseline by $0.84 \%$ and $1.14 \%$ for 1.2 and $1.8 \mathrm{mg}$ liraglutide compared with a reduction of $0.51 \%$ for glimepiride, with both liraglutide doses being superior to glimepiride (Figure 2). More liraglutide-treated subjects reached $\mathrm{HbA} 1 \mathrm{c}$ targets of $<7 \%$ and $<6.5 \%$ (51\% and $27 \%$, respectively for liraglutide $1.8 \mathrm{mg}$ ) compared to glimepiride (28\% and $16 \%$, respectively). Fasting and postprandial glucose levels were dose-dependently reduced with liraglutide, with both liraglutide doses being superior to glimepiride (FPG, -0.8 and $-1.4 \mathrm{mmol} / \mathrm{L}$ for liraglutide vs -0.3 for glimepiride; postprandial glucose, -1.7 and $-2.1 \mathrm{mmol} / \mathrm{L}$ for liraglutide vs -1.4 for glimepiride). Body weight declined over the first 16 weeks and thereafter stabilized on both liraglutide doses ( -2.1 and $-2.5 \mathrm{~kg}$, respectively), in contrast to a weight gain of $1.1 \mathrm{~kg}$ with glimepiride. ${ }^{36}$

The effect of adding liraglutide (1.2 or $1.8 \mathrm{mg}$ ) to therapy of patients inadequately controlled on metformin ( $1 \mathrm{~g}$ twice daily) plus rosiglitazone ( $8 \mathrm{mg}$ /day) was evaluated in LEAD-4, in 533 patients with T2DM (baseline HbA1c 8.3\%) treated for 26 weeks in a placebo-controlled trial; results were recently presented at the EASD. ${ }^{37}$ Addition of liraglutide significantly reduced $\mathrm{HbA} 1 \mathrm{c}$ to a greater extent than placebo, with both liraglutide doses being comparable (change from baseline, $-1.48 \%$ for both liraglutide doses vs $-0.54 \%$ for placebo). Of patients receiving liraglutide, 58\% and 54\% (1.2 and $1.8 \mathrm{mg}$ dose) reached target $\mathrm{HbA} 1 \mathrm{c}$ of $<7 \%$ (vs $28 \%$ for placebo), with $35 \%$ and $37 \%$ reaching values $<6.5 \%$ (14\% for placebo). The addition of liraglutide resulted in additional reductions in FPG and postprandial glucose, again with both liraglutide doses giving similar results (FPG, -2.2 and -2.4 $\mathrm{mmol} / \mathrm{L}$; postprandial glucose, -2.7 and $-2.6 \mathrm{mmol} / \mathrm{L}$ for the two liraglutide groups vs -0.4 and $-0.8 \mathrm{mmol} / \mathrm{L}$ for placebo). Whereas patients on placebo treatment experienced a small increase in body weight $(+0.6 \mathrm{~kg})$, those on liraglutide lost weight, with the effect being dose-dependent $(-1.0$ and -2.0 $\mathrm{kg}$, respectively for 1.2 and $1.8 \mathrm{mg}$ liraglutide). ${ }^{37}$

The LEAD-5 study examined the effect of adding liraglutide (1.8 $\mathrm{mg}$ once daily) to metformin ( $1 \mathrm{~g}$ twice daily) plus glimepiride (2-4 mg/day) in 581 patients with T2DM (baseline HbA1c 8.2\%) in a placebo-controlled trial; insulin glargine was used as an active comparator (open label). Preliminary results have been presented at both ADA and EASD. ${ }^{38,39}$ After 26 weeks, a greater reduction in $\mathrm{HbAlc}$ was obtained with liraglutide $(-1.33 \%)$ than with either insulin glargine $(-1.09 \%)$ or placebo $(-0.24 \%)$ and more patients reached target $\mathrm{HbA} 1 \mathrm{c}$ levels with liraglutide $(52 \%$ reaching $<7 \%$ and $36 \%$ reaching $<6.5 \%$ ) compared to insulin glargine (44\% and 23\%, respectively) or placebo (15\% and $11 \%$, respectively). Both active treatments reduced FPG to a similar extent $(\sim-1.6 \mathrm{mmol} / \mathrm{L})$, in contrast to placebo-treatment which resulted in a small increase $(+0.6 \mathrm{mmol} / \mathrm{L})$. In contrast to insulin glargine treatment, where patients gained weight $(+1.6 \mathrm{~kg})$, liraglutide resulted in a significant weight loss of $1.8 \mathrm{~kg}$ from baseline (placebo, $-0.4 \mathrm{~kg}$ from baseline). ${ }^{38,39}$

Finally, the LEAD-6 trial aimed to directly compare liraglutide ( $1.8 \mathrm{mg}$ once daily) with exenatide (10 $\mu \mathrm{g}$ twice daily)

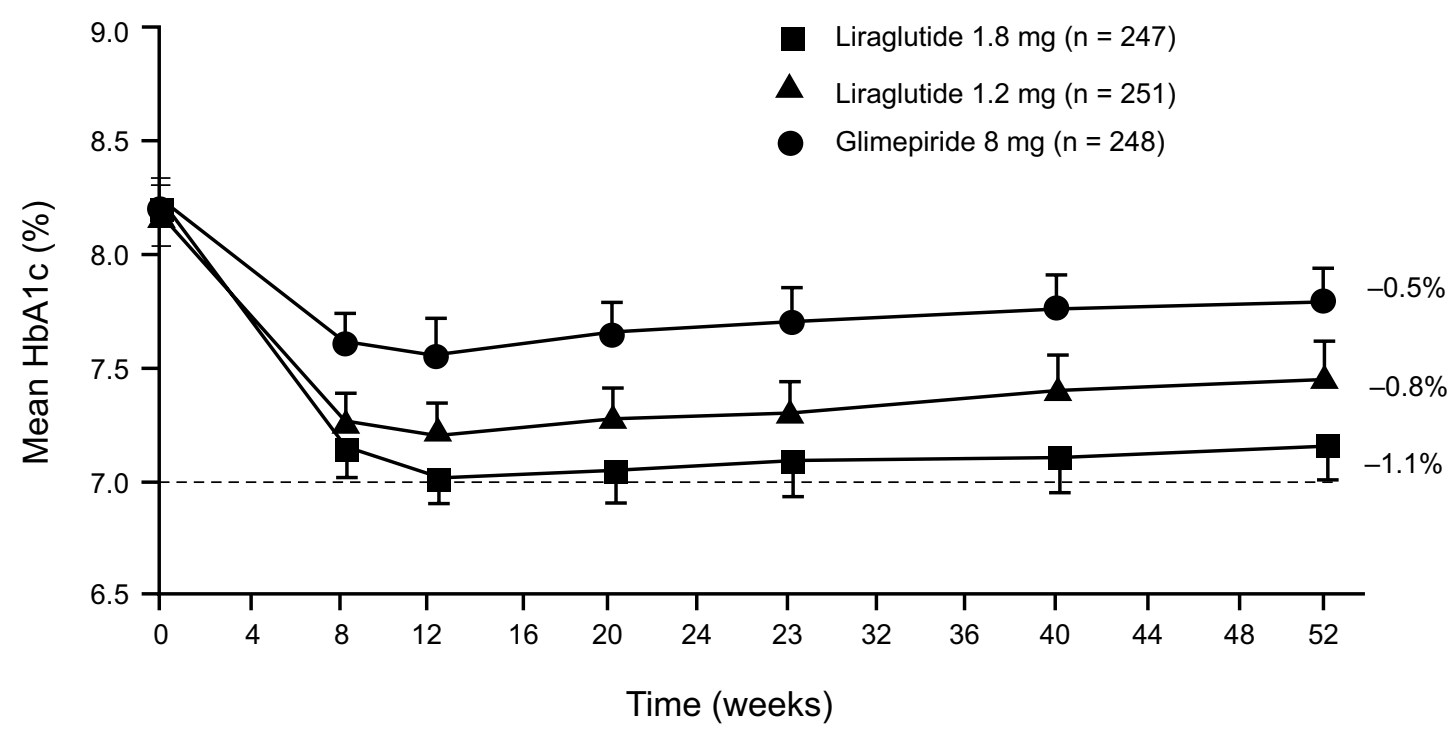

Figure 2 Effects of liraglutide monotherapy in LEAD-3. Eligible patients had been treated with diet and exercise only or up to half the highest dose of OAD monotherapy, which was discontinued at randomization. Adapted from The Lancet, Garber A, Henry R, Ratner R, et al. Liraglutide versus glimepiride monotherapy for type 2 diabetes (LEAD-3 Mono): a randomised, 52-week, phase III, double-blind, parallel-treatment trial, 2008 Sep 24. [Epub ahead of print], Copyright (C) 2008, with permission from Elsevier. ${ }^{36}$ 
in 464 patients who were inadequately treated with metformin and/or a sulfonylurea (baseline HbA1c 8.2\%). Preliminary results were presented at the Canadian Diabetes Association meeting. ${ }^{40}$ After 26 weeks, glycemic control was superior with liraglutide than with exenatide (HbAlc reductions of $1.12 \%$ vs $0.79 \% ; 54 \%$ vs $43 \%$ of subjects reaching target HbA1c of $<7 \%$; 35 vs $21 \%$ of subjects reaching HbA1c $<6.5 \%$; FPG reductions of 1.6 vs $0.6 \mathrm{mmol} / \mathrm{L}$; liraglutide vs exenatide). Body weight changes were similar for both groups ( $-3.2 \mathrm{~kg}$ for liraglutide, $-2.9 \mathrm{~kg}$ for exenatide). ${ }^{40} \mathrm{In}$ an extension of this study, patients originally randomized to exenatide were switched to liraglutide. After 14 weeks, $\mathrm{HbA} 1 \mathrm{c}$ in these subjects had dropped by a further $0.3 \%$, FPG by $0.9 \mathrm{mmol} / \mathrm{L}$ and body weight by $1 \mathrm{~kg}$, so that there was no longer any significant difference from those subjects who continued on liraglutide. ${ }^{41}$

\section{Islet cell effects}

In preclinical studies, liraglutide has been demonstrated to have protective effects on the $\beta$-cell. Thus, in cultured primary neonatal rat islets, Bregenholt et $\mathrm{al}^{42}$ showed that liraglutide inhibited both cytokine- and free fatty acid-induced apoptosis, while Friedrichsen et al $^{43}$ found that $\beta$-cell replication was increased, and similar effects in cultured human islets were recently reported..$^{44}$ In animal studies, $\beta$-cell mass was increased following treatment with liraglutide in rodent models of T2DM. ${ }^{45,46}$

While effects on $\beta$-cell mass have not yet been demonstrated in clinical studies (due primarily to a lack of suitable non-invasive technology), beneficial effects on islet cell function have been consistently seen. Thus, a single dose of liraglutide restores $\beta$-cell sensitivity to glucose, ${ }^{47}$ while 1 week of treatment improves glucose-induced insulin secretion and $\beta$-cell function (HOMA- $\beta$, insulin secretion during a hyperglycemic clamp, maximal insulin secretion after arginine infusion, proinsulin/insulin ratio) as well as having significant effects on $\alpha$-cell function (suppression of 24-hour glucagon profiles). ${ }^{25}$ The beneficial effects on $\beta$-cell function were maintained over 12 weeks of treatment with the highest dose of liraglutide in the study of Madsbad et al. ${ }^{27}$ Assessment of $\beta$-cell function after 14 weeks of treatment with liraglutide revealed improvements in firstand second-phase insulin secretion, together with increases in maximal (arginine-stimulated) insulin secretion during hyperglycemia. ${ }^{48}$ Another study, examining the effects of liraglutide under conditions of normal living, used mathematical modeling of insulin and glucose responses to meal ingestion, and also showed that liraglutide enhanced $\beta$-cell function. ${ }^{49}$ Finally, in the LEAD studies, liraglutide has been associated with improved $\beta$-cell function, which was similar to that observed with glimepiride, ${ }^{35,36}$ and superior to rosiglitazone $\mathrm{s}^{33,34}$ or exenatide. ${ }^{40}$

\section{Cardiovascular effects}

Small increases in pulse rate of 2 to 3 beats per minute have been observed throughout the LEAD studies, ${ }^{35-37}$ although the clinical significance (if any) of this is unknown. However, of great interest are the consistent observations that systolic blood pressure is significantly decreased. Vilsbøll et $\mathrm{al}^{30}$ found reductions with all liraglutide doses, by up to $7.9 \mathrm{mmHg}$ compared to placebo after 14 weeks of treatment. In LEAD-2 and LEAD-3, systolic blood pressure changes favored liraglutide over glimepiride (reductions from baseline of 2-4 mmHg with liraglutide). ${ }^{35,36}$ Reductions in systolic blood pressure were also reported for the other LEAD studies, with the effects already apparent at the first assessment point ( 2 weeks post-randomization). ${ }^{50}$ No significant changes in diastolic blood pressure were reported in any of the studies.

\section{Adverse events and safety Gastrointestinal side effects}

In common with other GLP-1 receptor agonists, such as exenatide, gastrointestinal adverse effects (nausea, vomiting and diarrhea) are the most common adverse events seen in the clinical trials with liraglutide, with the incidences appearing to be dose-related.

Thus, throughout the LEAD studies, up to $44 \%$ of subjects receiving liraglutide at the highest dose $(1.8 \mathrm{mg})$ reported gastrointestinal side effects, with nausea being the most frequently reported event, occurring in up to $40 \%$ of subjects. Generally, nausea was seen predominantly in the first few weeks after initiation of treatment; in LEAD-2, less than $10 \%$ of the subjects were experiencing nausea on a weekly basis by the fourth week. ${ }^{35}$ In LEAD-1 and LEAD-5, nausea was reported by less than $4 \%$ of subjects by week 2 to $4,33,34,38,39$ while in LEAD-4, the incidence of nausea had decreased to the same level as in the placebo group after 16 weeks. ${ }^{37}$ Diarrhea was reported by $15 \%$ to $18 \%$ of subjects compared to less than $10 \%$ of subjects on comparator agents, ${ }^{35,36}$ and vomiting by $\sim 10 \%$ of subjects (vs $4 \%$ on glimepiride). ${ }^{35}$ However, it is noteworthy that relatively few subjects withdrew from the studies because of gastrointestinal side effects associated with liraglutide. In LEAD-2, only $5 \%$ of all liraglutide treated subjects withdrew, with the majority of those discontinuing during the first 
month of treatment, ${ }^{35}$ while in LEAD-3, between $2 \%$ and $4 \%$ of subjects withdrew. ${ }^{36}$ In a specifically designed sub-study, a Gastrointestinal System Rating Scale (GSRS; a validated self-reporting method) was used to quantify the duration and intensity of gastrointestinal adverse events during 14 weeks of liraglutide treatment $(0.65,1.25$ and $1.9 \mathrm{mg}) .{ }^{51}$ Although liraglutide increased gastrointestinal symptoms, the average rating was low (maximum 2 on a 7 -point scale), with the self-reported increase in events occurring mainly during the first two weeks of treatment, and decreasing thereafter. Only the reflux GSRS score showed a significant dose-related relationship. For indigestion and constipation, only the $1.25 \mathrm{mg}$ dose was significantly greater than placebo, while there was no difference between liraglutide and placebo with respect to scores for diarrhea and abdominal pain. ${ }^{51}$

\section{Hypoglycemia}

Overall, the risk of hypoglycemia with liraglutide is low, due to the glucose-dependency of its insulinotropic and glucagonostatic effects. Under conditions of a stepwise hypoglycemic clamp, insulin secretion is no longer enhanced by liraglutide $(7.5 \mu \mathrm{g} / \mathrm{kg})$ when blood glucose levels are reduced from 3.7 to $3.0 \mathrm{mmol} / \mathrm{L}$ and there is no impairment of hypoglycemia-induced glucagon secretion, ${ }^{52}$ suggesting that the counter-regulatory response to hypoglycemia is unaffected by liraglutide. Thus, in the early clinical studies, minor hypoglycemia (defined as $<3.1 \mathrm{mmol} / \mathrm{L}$ ) was rarely observed. ${ }^{27-30}$

Throughout the LEAD program, the incidence of minor hypoglycemia with liraglutide has also been very low, ranging from 0.03 up to 1.9 events per year. ${ }^{33-40}$ Overall, in the studies with active comparators, the incidence has been similar to that observed with metformin or rosiglitazone, ${ }^{33,34}$ and lower than that seen with glimepiride ${ }^{35,36}$ or exenatide. ${ }^{40}$ Major hypoglycemia has only rarely been seen. In LEAD-1, one major hypoglycemic episode was reported, although this was considered to be related to the background sulfonylurea therapy, ${ }^{33,34}$ while in LEAD-5, 2.2\% of subjects experienced a major hypoglycemic event in the liraglutide arm (vs none in the other arms). ${ }^{38,39}$

\section{Pancreatitis}

Novo Nordisk has reported a low number of incidents of acute pancreatitis in patients taking liraglutide in the clinical trials, although the incidence rate is in the normal range for T2DM; no cases of hemorrhagic or necrotizing pancreatitis have been seen. ${ }^{41}$ In LEAD-3, 2 participants (out of 498 taking liraglutide) experienced pancreatitis, 1 after 197 days
(1.2 $\mathrm{mg}$ dose) and 1 after 333 days (1.8 $\mathrm{mg}$ dose); both recovered and 1 continued in the study. ${ }^{36}$ In LEAD-2, 1 subject (out of 724) in the liraglutide-exposed group (1.2 mg) and 1 (out of 242) in the glimepiride group withdrew because of acute pancreatitis; after hospitalization for 7 days, both recovered. ${ }^{35}$ No incidents of pancreatitis were reported in the LEAD-4 trial. ${ }^{37}$

\section{Antibodies}

Formation of anti-liraglutide antibodies is reported to be low and not to be associated with loss of efficacy. ${ }^{41}$ In LEAD-2, antibodies were detected in only 1 (out of 85) of the subjects who did not enter the open-label continuation phase of the study at week 26, and these were not immuno-neutralizing and showed no cross-reactivity with GLP- $1 .{ }^{53}$ Liraglutide antibodies were found in $9.3 \%$ to $12.7 \%$ of liraglutidetreated subjects in LEAD-1,33,34 and in 9.8\% in LEAD-5 after 26 weeks. ${ }^{38,39}$

\section{Discussion}

Liraglutide belongs to one class of the so-called incretinbased therapies, namely the incretin mimetics (the other class being the DPP-4 inhibitors), which takes advantage of the known effects of the intestinal hormone, GLP-1. At present, clinical experience with these agents is still relatively limited, with exenatide being the only incretin mimetic so far to be approved for treatment of T2DM (launched in 2005). In clinical trials, both liragutide and exenatide have been well tolerated, with gastrointestinal adverse events (nausea, diarrhea, vomiting) being the most common side effects (reported by $\sim 50 \%$ of subjects). However, gradual dose escalation seems effective in reducing the incidence and severity of these gastrointestinal symptoms, such that in the majority of trials, their frequency was highest at the initiation of therapy and declined thereafter. Some concern over the safety of the incretin mimetics first arose in 2007, after the FDA issued a warning following reports of acute pancreatitis in patients taking exenatide; 30 cases were reported, although the diagnosis of acute pancreatitis (based on the presence of nausea, vomiting, abdominal pain, which notably are also known side effects of the incretin mimetics themselves) was confirmed by laboratory test in only 17 of the cases, and 27 of the cases had at least one other risk factor. Subsequently a total of 89 cases in patients on exenatide had been reported up to the end of September 2007. In August 2008, the FDA reported 6 new cases of hemorrhagic or necrotizing pancreatitis in patients using exenatide, and 6 deaths in patients who had experienced pancreatitis have been reported, although 
other confounding factors were involved. ${ }^{54,55}$ However, the rates of pancreatitis with exenatide ${ }^{56}$ or liraglutide ${ }^{41}$ are below those reported for the background T2DM population, which itself has a 2.8-fold greater incidence than the general population. ${ }^{57}$ At present, a definitive causal relationship between incretin mimetics and pancreatitis has not been established, but a possible association cannot yet be fully excluded.

Consistent with the glucose dependency of its mechanism of action, the incidence of hypoglycemia has been very low with liraglutide, although occasional episodes of severe hypoglycemia have been noted when used in combination with sulfonylurea. ${ }^{33,34,38,39}$ A greater incidence of hypoglycemia has also been observed when exenatide is used together with sulfonylurea, ${ }^{58,59}$ and may perhaps reflect the enhanced $\beta$-cell function brought about by the GLP-1 agonists. Alternatively, there is some preclinical evidence that the sulfonylurea itself can uncouple the glucose-dependency of GLP-1's insulinotropic action. ${ }^{60}$

Weight loss with liraglutide in some trials has been inconsistent. In some of the earlier studies, no clear doseresponse relationship was apparent, ${ }^{26-28}$ but this might be explained by the doses used in these studies not being optimal. With the higher doses (up to $1.9 \mathrm{mg}$ ), weight reductions have generally been seen consistently, although rather surprisingly, in LEAD-1, the weight change was not different from placebo. ${ }^{33,34}$ It has also been questioned whether nausea contributes to the weight loss observed with the GLP-1 analogs. In a sub-group analysis in LEAD-3, there were small trends for the magnitude of weight loss to be greater in subjects experiencing nausea for more than 7 days compared to those with none or less than 7 days' nausea (eg, for $1.8 \mathrm{mg}$ liraglutide, the weight change was $-3.4 \mathrm{~kg}$ for participants experiencing nausea for more than 7 days vs $-2.3 \mathrm{~kg}$ for those with none or less than 7 days' nausea), although the differences were not significant for any treatment. ${ }^{36}$ Liraglutide appears not to affect energy expenditure, at least in doses up to $0.6 \mathrm{mg},{ }^{26}$ while with higher doses (up to $1.8 \mathrm{mg}$ ), there was only a non-significant trend for resting energy expenditure to be higher. ${ }^{61}$ It therefore appears that the major cause of weight loss is due to reduction in food intake. Thus, in sub-studies using visual analog scales, liraglutide reduced the feelings of hunger and prospective food intake, while increasing the feeling of fullness, together leading to a lower energy intake by up to $18 \%$ during an ad libitum meal. ${ }^{61,62}$

Any anti-diabetic agent that shows beneficial effects on the development of diabetic macrovascular complications will be welcome. Cardioprotective effects of GLP-1 have been observed preclinically, ${ }^{63}$ and it is therefore of particular interest that liraglutide treatment has been associated with clinically significant reductions in systolic blood pressure. This may be partly accounted for by concomitant body weight loss, although based on the profiles over time, Nauck et $\mathrm{al}^{35}$ concluded that weight reductions could not fully explain the blood pressure changes. It is therefore noteworthy that reductions in blood pressure are also observed with the DPP-4 inhibitors, which are weight neutral. ${ }^{64,65}$ Additionally, there is some evidence that the weight loss induced by liraglutide comes pimarily from loss of fat (particularly visceral fat, which is a known cardiovascular risk factor), rather than lean tissue. ${ }^{66}$ Whether these changes will be associated with reductions in macrovascular events will become apparent as clinical experience with these agents is gained and as data from longer duration trials with cardiovascular endpoints become available.

It is clear from the clinical trials that liraglutide improves glycemic control via effects on both fasting and postprandial glucose. The islet effects are likely to be of particular importance, since liraglutide has been consistently shown to improve $\beta$-cell function, leading to increased fasting insulin levels and improved maximal postprandial insulin levels. ${ }^{67}$ Additionally, effects on the $\alpha$-cell are also likely to be important, given liraglutide's powerful glucagonstatic effect. ${ }^{25}$ However, unlike exenatide, where delayed gastric emptying appears to play a major role in the drug's antihyperglycemic action, ${ }^{68}$ delayed gastric emptying probably accounts for a smaller part of the lower postprandial glucose levels obtained with liraglutide. Thus, while a single dose of liraglutide does significantly delay gastric emptying, ${ }^{24}$ liraglutide was without effect on gastric emptying when administered over several weeks, although the doses used in those early studies may not have been optimal. ${ }^{25,26}$ Subsequently, studies using higher doses (up to $1.8 \mathrm{mg}$ ) have indicated that liraglutide is associated with a minor delay in gastric emptying, particularly over the first hour. ${ }^{61,67}$ This difference in the relative effects of exenatide and liraglutide on gastric emptying may be explained by the more prolonged exposure to liraglutide leading to some tachyphylaxis of the gastric emptying effect, speculation which is supported by the observation that a long-acting formulation of exenatide, designed for onceweekly administration, has a less pronounced effect on gastric emptying (and postprandial glucose excursions) than exenatide given twice daily. ${ }^{69}$ Although there is some evidence that some of the effects of endogenous GLP-1 may be mediated via interaction with autonomic nerves, at present it is unclear whether any of the effects of exogenously administered GLP-1 analogs depend on autonomic function. However, it 
is noteworthy that GLP-1 is still able to normalize fasting glucose levels when given intravenously to patients with advanced diabetes, long after secondary sulfonylurea failure, in whom neuropathy is present. ${ }^{70}$ Furthermore, a recent study indicates that the gastric emptying effects of exenatide are unaffected by the presence of autonomic neuropathy. ${ }^{68}$

Early studies with native GLP-1 indicated that increasing the exposure to the peptide resulted in greater efficacy with respect to lowering blood glucose levels, ${ }^{71,72}$ and a similar situation seems to exist with the GLP-1 analogs. The first GLP-1 analog to be used for treatment of T2DM, exenatide, has a pharmacokinetic profile necessitating twice daily administration. In clinical use, exenatide gives sustained reductions in HbA1c levels, ${ }^{73}$ but because of its relatively short plasma half-life, exposure to the drug is not optimal, even with twice-daily administration, particularly so in the overnight period. Liraglutide, with its longer plasma half-life, provides 24-hour coverage, and the preliminary results of the head-to-head comparison indicate that glycemic control is superior with liraglutide. ${ }^{40}$ Similar results have also been seen with the once-weekly formulation of exenatide. ${ }^{69}$ Moreover, the flatter drug profile obtained with these longer-acting analogs ${ }^{69,74}$ also seems to reduce gastrointestinal symptoms. The DPP-4 inhibitors also increase intact GLP-1 levels over the full 24-hour period, but the pattern of exposure differs. Thus, whereas the GLP-1 analogs raise agonist plasma concentrations into the pharmacological range throughout the vascular system, the DPP-4 inhibitors typically increase intact GLP-1 concentrations by only 2 - to 3 -fold, ${ }^{75}$ although with concentrations locally in the gut and portal vein being much higher than those in the periphery. ${ }^{76}$ It has been argued that GLP-1 may exert many of its actions locally or in the hepato-portal bed, ${ }^{77}$ and perhaps because of this, the DPP-4 inhibitors are effective, despite the low systemic GLP-1 concentrations attained. Like the GLP-1 analogs, DPP-4 inhibitors give sustained reductions in $\mathrm{HbAlc},{ }^{78}$ and are associated with improvements in $\beta$-cell function. ${ }^{79,80}$ Similarly, $\alpha$-cell function is also improved with DPP-4 inhibitors, ${ }^{81}$ but unlike the GLP-1 analogs, there are only minimal effects of gastric emptying and appetite is unaffected, ${ }^{82}$ meaning that the DPP-4 inhibitors are best described as being body weight neutral. While the mechanism of action of the GLP-1 analogs relies only on GLP-1 receptor signaling, the DPP-4 inhibitors are believed to exert their effects via endogenous GLP-1 and GIP, but precisely how this difference affects the clinical profiles of the two classes of agents remains to be elucidated. The HbA1c-lowering efficacy of the two classes of incretin-based therapies has not yet been directly compared, although a mechanistic study over 2 weeks indicated that while both agents had similar effects on FPG, exenatide had a greater effect on breakfast and dinner (but not lunch) postprandial glucose ${ }^{82}$ presumably related to the potent effect of exenatide to reduce gastric emptying.

The positioning of liraglutide in the therapeutic regimen remains to be determined. In support of an early use, the LEAD program indicates that liraglutide is effective in monotherapy, and even superior to sulfonylurea, with the additional advantage of weight loss and less hypoglycemia. ${ }^{36}$ Moreover, as add-on therapy to a single OAD, it is non-inferior to sulfonylurea, ${ }^{35}$ and superior to thiazolidinedione, ${ }^{33,34}$ again with the favorable effect on weight. Moreover, various sub-group analyses seem to indicate that the degree of improvement is, at least partially, related to the stage of the disease. Thus, subjects previously treated with diet and exercise achieved greater $\mathrm{HbA} 1 \mathrm{c}$ reductions than those who had previously been on OAD monotherapy in LEAD-3. ${ }^{36}$ In LEAD-1, subjects previously on OAD monotherapy achieved greater $\mathrm{HbA} 1 \mathrm{c}$ reductions than those on previous combination therapy, ${ }^{33,34}$ while in LEAD-2, there was a tendency for those who were on pre-study monotherapy to achieve greater HBA1c reductions than those on previous combination therapy. ${ }^{35}$ However, whether there will be patient (and physician) acceptance of using an injectable agent early in the management of the disease has yet to be determined. There is also a place for liraglutide later on in the course of the disease, with liraglutide giving significant reductions in $\mathrm{HbA} 1 \mathrm{c}$ when used as an additional agent in patients already receiving combination therapy with 2 or 3 OADs, ${ }^{37-39}$ and compared with insulin glargine, liraglutide gave better glycemic control without the weight gain. ${ }^{37,38}$ Particularly the weight changes may help to encourage the use of this agent, since, with the exception of the incretinbased therapies (GLP-1 analogs and DPP-4 inhibitors) and metformin, all other agents, including insulin, are associated with weight gain. However, if lasting effects on the $\beta$-cell are demonstrated, then liraglutide (and other incretin-based therapies) may be able to ameliorate the progressive deterioration in glycemic control, which, at present, seems an inescapable characteristic of T2DM. It is therefore encouraging that preliminary results from a study in obese non-diabetic subjects, where around $30 \%$ of the participants had some signs of prediabetes at randomization, indicated that liraglutide was associated with a reduction in the number of prediabetic subjects after 1 year of treatment. ${ }^{83}$ The success of liraglutide will ultimately depend upon not only its efficacy and durability in terms of glycemic control 
and body weight, but also upon its possible impact on late diabetic complications, and compliance issues such as tolerability/safety, convenience of use and cost.

\section{Disclosures}

Consultancy/advice: Merck \& Co, Servier; Lecture fees: Merck \& Co, Novartis, Novo Nordisk; Spouse: Employed by Merck \& Co, holds stock/shares in Merck \& Co, Novo Nordisk.

\section{References}

1. Nathan DM, Buse JB, Davidson MB, et al. Medical management of hyperglycemia in type 2 diabetes: a consensus algorithm for the initiation and adjustment of therapy. Diabetes Care. 2009;32:193-203.

2. UK Prospective Diabetes Study (UKPDS) Group. Intensive bloodglucose control with sulphonylureas or insulin compared with conventional treatment and risk of complications in patients with type 2 diabetes (UKPDS 33). Lancet. 1998;352:837-853.

3. UK Prospective Diabetes Study (UKPDS) Group. Effect of intensive blood-glucose control with metformin on complications in overweight patients with type 2 diabetes (UKPDS 34). Lancet. 1998; 352:854-865.

4. Kahn SE, Haffner SM, Heise MA, et al. Glycemic durability of rosiglitazone, metformin, or glyburide monotherapy. $N$ Engl J Med. 2006;355:2427-2443.

5. Baggio LL, Drucker DJ. Biology of incretins: GLP-1 and GIP. Gastroenterology. 2007;132:2131-2157.

6. Holst JJ. The physiology of glucagon-like peptide 1. Physiol Rev. 2007;87:1409-1439.

7. Holst JJ, Vilsbøll T, Deacon CF. The incretin system and its role in type 2 diabetes mellitus. Mol Cell Endocrinol. 2009;297:127-136.

8. Nauck MA, Kleine N, Orskov C, Holst JJ, Willms B, Creutzfeldt W. Normalization of fasting hyperglycaemia by exogenous glucagon-like peptide 1 (7-36 amide) in type 2 (non-insulin-dependent) diabetic patients. Diabetologia. 1993;36:741-744.

9. Rachman J, Barrow BA, Levy JC, Turner RC. Near-normalisation of diurnal glucose concentrations by continuous administration of glucagon-like peptide-1 (GLP-1) in subjects with NIDDM. Diabetologia. 1997;40:205-211.

10. Zander M, Madsbad S, Madsen JL, Holst JJ. Effect of 6-week course of glucagon-like peptide 1 on glycaemic control, insulin sensitivity, and beta-cell function in type 2 diabetes: a parallel-group study. Lancet. 2002;359:824-830.

11. Deacon CF, Nauck MA, Toft-Nielsen M, Pridal L, Willms B, Holst JJ. Both subcutaneously and intravenously administered glucagon-like peptide I are rapidly degraded from the NH2-terminus in type II diabetic patients and in healthy subjects. Diabetes. 1995;44:1126-1131.

12. Deacon CF, Pridal L, Klarskov L, Olesen M, Holst JJ. Glucagon-like peptide 1 undergoes differential tissue-specific metabolism in the anesthetized pig. Am J Physiol. 1996;271:E458-E464.

13. Vilsbøll T, Agersø H, Krarup T, Holst JJ. Similar elimination rates of glucagon-like peptide- 1 in obese type 2 diabetic patients and healthy subjects. J Clin Endocrinol Metab. 2003;88:220-224.

14. Plamboeck A, Holst JJ, Carr RD, Deacon CF. Neutral endopeptidase 24.11 and dipeptidyl peptidase IV are both mediators of the degradation of glucagon-like peptide 1 in the anaesthetised pig. Diabetologia. 2005;48(9):1882-1890.

15. Simonsen L, Holst JJ, Deacon CF. Exendin-4, but not glucagon-like peptide-1, is cleared exclusively by glomerular filtration in anaesthetised pigs. Diabetologia. 2006;49:706-712.
16. Deacon CF, Knudsen LB, Madsen K, Wiberg FC, Jacobsen O, Holst JJ. Dipeptidyl peptidase IV resistant analogues of glucagon-like peptide-1 which have extended metabolic stability and improved biological activity. Diabetologia. 1998;41:271-278.

17. Chen YE, Drucker DJ. Tissue-specific expression of unique mRNAs that encode proglucagon-derived peptides or exendin 4 in the lizard. J Biol Chem. 1997;272:4108-4115.

18. Knudsen LB, Nielsen PF, Huusfeldt PO, et al. Potent derivatives of glucagon-like peptide-1 with pharmacokinetic properties suitable for once daily administration. J Med Chem. 2000;43:1664-1669.

19. Agersø H, Jensen LB, Elbrønd B, Rolan P, Zdravkovic M. The pharmacokinetics, pharmacodynamics, safety and tolerability of NN2211, a new long-acting GLP-1 derivative, in healthy men. Diabetologia. 2002;45:195-202.

20. Bjornsdottir I, Olsen A, Larsen U, et al. Metabolism and excretion of the once-daily human GLP-1 analogue liraglutide in healthy subject and its in vitro degradation by dipeptidyl peptidase IV and neutral endopeptidase. Diabetologia. 2008;51(Suppl 1):S356 (abstract).

21. Jacobsen LV, Hindsberger C, Robson R, Zdravkoviv M. Pharmacokinetics of the long-acting human GLP-1 analogue liraglutide in subjects with renal impairment. Diabetes. 2007;56 Suppl 1:A137 (abstract).

22. Damholt B, Golor G, Wierich W, Pedersen P, Ekblom M, Zdravkovic M. An open-label, parallel group study investigating the effects of age and gender on the pharmacokinetics of the once-daily glucagon-like peptide-1 analogue liraglutide. J Clin Pharmacol. 2006;46:635-641.

23. Irie S, Matsumura Y, Zdravkovic M, Jacobsen LV, Kageyama S Tolerability, pharmacokinetics and pharmacodynamics of the oncedaily human GLP-1 analog liraglutide in Japanese healthy subjects: a randomized, double-blind, placebo-controlled dose-escalation study. Int J Clin Pharmacol Ther. 2008;46:273-279.

24. Juhl CB, Hollingdal M, Sturis J, et al. Bedtime administration of NN2211, a long-acting GLP-1 derivative, substantially reduces fasting and postprandial glycemia in type 2 diabetes. Diabetes. 2002; $51: 424-429$.

25. Degn KB, Juhl CB, Sturis J, et al. One week's treatment with the long-acting glucagon-like peptide 1 derivative liraglutide (NN2211) markedly improves $24-\mathrm{h}$ glycemia and alpha- and beta-cell function and reduces endogenous glucose release in patients with type 2 diabetes. Diabetes. 2004;53:1187-1194.

26. Harder H, Nielsen L, Tu DT, Astrup A. The effect of liraglutide, a long-acting glucagon-like peptide 1 derivative, on glycemic control, body composition, and 24-h energy expenditure in patients with type 2 diabetes. Diabetes Care. 2004;27:1915-1921.

27. Madsbad S, Schmitz O, Ranstam J, Jakobsen G, Matthews DR. Improved glycemic control with no weight increase in patients with type 2 diabetes after once-daily treatment with the long-acting glucagonlike peptide 1 analog liraglutide (NN2211): a 12-week, double-blind, randomized, controlled trial. Diabetes Care. 2004;27:1335-1342.

28. Feinglos MN, Saad MF, Pi-Sunyer FX, An B, Santiago O. Effects of liraglutide (NN2211), a long-acting GLP-1 analogue, on glycaemic control and bodyweight in subjects with Type 2 diabetes. Diabet Med. 2005;22:1016-1023.

29. Nauck MA, Hompesch M, Filipczak R, Le TD, Zdravkovic M, Gumprecht J. Five weeks of treatment with the GLP-1 analogue liraglutide improves glycaemic control and lowers body weight in subjects with type 2 diabetes. Exp Clin Endocrinol Diabetes. 2006;114:417-423.

30. Vilsbøll T, Zdravkovic M, Le-Thi T, et al. Liraglutide, a long-acting human glucagon-like peptide-1 analog, given as monotherapy significantly improves glycemic control and lowers body weight without risk of hypoglycemia in patients with type 2 diabetes. Diabetes Care. 2007;30:1608-1610.

31. Seino Y, Rasmussen MF, Zdravkovic M, Kaku K. Dose-dependent improvement in glycemia with once-daily liraglutide without hypoglycemia or weight gain: A double-blind, randomized, controlled trial in Japanese patients with type 2 diabetes. Diabetes Res Clin Pract. 2008:81:161-168 
32. Matsumoto K, Miyake S, Yano M, et al. Glucose tolerance, insulin secretion, and insulin sensitivity in nonobese and obese Japanese subjects. Diabetes Care. 1997;20:1562-1568.

33. Marre M, Shaw J, Brandle M, et al. Liraglutide, a once daily human GLP-1 analog, added to a sulphoflurea (SU) offers significantly better glycemic control and favorable weight change compared with rosiglitazone and SU combination therapy in subjects with type 2 diabetes. Diabetes. 2008;57 Suppl 1:A4 (abstract).

34. Marre M, Shaw J, Brandle M, et al. Liraglutide added to a sulphonylurea (SU) offers significantly better glycaemic control and favourable weight change compared with rosiglitazone and SU combination therapy in T2DM. Diabetologia. 2008;51 Suppl 1:S359 (abstract).

35. Nauck M, Frid A, Hermansen K, et al. Efficacy and safety comparison of liraglutide, glimepiride, and placebo, all in combination with metformin in type 2 diabetes mellitus (LEAD-2 Met). Diabetes Care. 2009;32:84-90

36. Garber A, Henry R, Ratner R, et al. Liraglutide versus glimepiride monotherapy for type 2 diabetes (LEAD-3 Mono): a randomised, 52-week, phase III, double-blind, parallel-treatment trial. Lancet. 2008 Sep 24. [Epub ahead of print].

37. Zinman B, Gerich J, Buse J, et al. Effect of the GLP-1 analogue liraglutide on glycaemic control and weight reduction in patients on metformin and rosiglitazone: a randomised double-blind placebo controlled trial. Diabetologia. 2008;51 Suppl 1:S359 (abstract)

38. Russell-Jones D, Vaag A, Schmitz O, et al. Significantly better glycemic control and weight reduction with liraglutide, a once-daily human GLP-1 analog, compared with insulin glargine: all as add-on to metformin and a sulfonylurea in type 2 diabetes. Diabetes. 2008;57 Suppl 1:A159 (abstract).

39. Russell-Jones D, Vaag A, Schmitz O, et al. Significantly better glycaemic control/weight reduction with human GLP-1 analogue liraglutide, than with insulin glargine: all as add-on to metformin + sulphonylurea in type 2 diabetes. Diabetologia. 2008;51 Suppl 1:S68 (abstract).

40. Blonde L, Rosenstock J, Sesti G, et al. Liraglutide: superior glycemic control vs exenatide when added to metformin and/or SU in type 2 diabetes. 2008 CDA/CSEM Professional Conference and Annual Meetings, abstract 107. [accessed 3 December 2008]. Available from: http://www.diabetes.ca/files/for-professionals/conference-abstractbook.pdf

41. Novo Nordisk [website]. 26th October 2008 Capital markets day: liraglutide [accessed 26 November 2008]. Available from: http:// www.novonordisk.com/images/investors/capital-markets-day/2008/ Liraglutide.pdf

42. Bregenholt S, Møldrup A, Blume N, et al. The long-acting glucagonlike peptide-1 analogue, liraglutide, inhibits beta-cell apoptosis in vitro. Biochem Biophys Res Commun. 2005;330:577-584.

43. Friedrichsen BN, Neubauer N, Lee YC, et al. Stimulation of pancreatic beta-cell replication by incretins involves transcriptional induction of cyclin D1 via multiple signalling pathways. J Endocrinol. 2006;188:481-492.

44. Prazak R, Rutti S, Ellingsgaard H, Knudsen LB, Donath M. Liraglutide induces cell proliferation and protects from interleukin-1 beta-induced $\beta$-cell apoptosis in human islets. Diabetologia. 2008;51 Suppl 1:S212 (abstract).

45. Rolin B, Larsen MO, Gotfredsen CF, et al. The long-acting GLP-1 derivative NN2211 ameliorates glycemia and increases beta-cell mass in diabetic mice. Am J Physiol Endocrinol Metab. 2002;283: E745-E752.

46. Sturis J, Gotfredsen CF, Rømer J, et al. GLP-1 derivative liraglutide in rats with beta-cell deficiencies: influence of metabolic state on beta-cell mass dynamics. Br J Pharmacol. 2003;140:123-132.

47. Chang AM, Jakobsen G, Sturis J, et al. The GLP-1 derivative NN2211 restores beta-cell sensitivity to glucose in type 2 diabetic patients after a single dose. Diabetes. 2003;52:1786-1791.
48. Vilsbøll T, Brock B, Perrild H, et al. Liraglutide, a once-daily human GLP-1 analogue, improves pancreatic B-cell function and argininestimulated insulin secretion during hyperglycaemia in patients with Type 2 diabetes mellitus. Diabet Med. 2008;25:152-156.

49. Mari A, Degn K, Brock B, Rungby J, Ferrannini E, Schmitz O. Effects of the long-acting human glucagon-like peptide-1 analog liraglutide on beta-cell function in normal living conditions. Diabetes Care. 2007; 30:2032-2033.

50. Colagiuri S, Frid A, Zradvkovic M, et al. Liraglutide, a human GLP-1 analogue, reduces systolic blood pressure in subjects with type 2 diabetes. Diabetologia. 2008;51 Suppl 1:S360 (abstract).

51. Horowitz M, Vilsbøll T, Zdravkovic M, Hammer M, Madsbad S. Patient-reported rating of gastrointestinal adverse effects during treatment of type 2 diabetes with the once-daily human GLP-1 analogue, liraglutide. Diabetes Obes Metab. 2008;10:593-596.

52. Nauck MA, El-Ouaghlidi A, Hompesch M, Jacobsen J, Elbroend B. No impairment of hypoglycemia counterregulation via glucagon with NN2211, a GLP-1 derivative, in subjects with type 2 diabetes. Diabetes. 2003;52 Suppl 1:A128 (abstract).

53. Hermansen K, Nauck MA, Frid A, et al. Liraglutide, a once-daily human GLP-1 analogue, in type 2 diabetes provides similar glycaemic control with reduced bodyweight compared with glimepiride when added to metformin (LEAD-2). Diabetologia. 2008;51 Suppl 1:S358 (abstract).

54. Ahmad SR, Swann J. Exenatide and rare adverse events. N Engl J Med. 2008:358:1970-1971.

55. Bain SC, Stephens JW. Exenatide and pancreatitis: an update. Expert Opin Drug Saf. 2008;7:643-644.

56. Reutens AT, Shaw JE. Incretin mimetics and enhancers: clinical applications. Aust Prescr. 2008;31:104-108.

57. Noel RA, Braun DK, Patterson RE, Bloomgren G. Increased risk of acute pancreatitis observed in patients with type 2 diabetes. Pancreas. 2008;37:487 (abstract).

58. Buse JB, Henry RR, Han J, Kim DD, Fineman MS, Baron AD. Effects of exenatide (exendin-4) on glycemic control over 30 weeks in sulfonylurea-treated patients with type 2 diabetes. Diabetes Care. 2004;27:2628-2635.

59. Kendall DM, Riddle MC, Rosenstock J, et al. Effects of exenatide (exendin-4) on glycemic control over 30 weeks in patients with type 2 diabetes treated with metformin and a sulfonylurea. Diabetes Care. 2005;28:1083-1091.

60. de Heer J, Holst JJ. Sulfonylurea compounds uncouple the glucose dependence of the insulinotropic effect of glucagon-like peptide 1 . Diabetes. 2007;56:438-443.

61. Horowitz M, Flint A, Doran S, et al. Effects of the once-daily human GLP-1 analogue liraglutide on appetite and energy intake in type 2 diabetes. Diabetologia. 2008;51 Suppl 1:S355 (abstract).

62. Flint A, Kaptiza C, Hindsberger C, Zdravkovic M. The once daily human GLP-1 analogue liraglutide decreases postprandial hunger and energy intake. Diabetes. 2008;57 Suppl 1:A165 (abstract).

63. Bose AK, Mocanu MM, Carr RD, Brand CL, Yellon DM. Glucagon-like peptide 1 can directly protect the heart against ischemia/reperfusion injury. Diabetes. 2005;54:146-151.

64. Bosi E, Byiers SR, Cohen SE. Vildagliptin significantly decreases blood pressure (BP) in hypertensive patients (pts) with type 2 diabetes (T2DM) compared with metformin. Diabetes. 2007;56 Suppl 1:A139 (abstract)

65. Mistry GC, Maes AL, Lasseter KC, et al. Effect of sitagliptin, a dipeptidyl peptidase-4 inhibitor, on blood pressure in nondiabetic patients with mild to moderate hypertension. J Clin Pharmacol. 2008;48: 592-598.

66. Jendle J, Nauck MA, Matthews DR, et al. The reduction in bodyweight with liraglutide, a once-daily human GLP-1 analogue for type 2 diabetes, primarily comes from fat tissue and the fat tissue lost is predominantly visceral fat. Diabetologia. 2008;51 Suppl 1:S318 (abstract). 
67. Flint A, Kapitza C, Hindsberger C, Zdravkovic M. The once-daily human GLP-1 analogue liraglutide improves both absolute- and baselinecorrected postprandial glucose levels. Diabetologia. 2008;51 Suppl 1: S354 (abstract).

68. Linnebjerg H, Park S, Kothare PA, et al. Effect of exenatide on gastric emptying and relationship to postprandial glycemia in type 2 diabetes. Regul Pept. 2008;151:123-129.

69. Drucker DJ, Buse JB, Taylor K, et al. Exenatide once weekly versus twice daily for the treatment of type 2 diabetes: a randomised, openlabel, non-inferiority study. Lancet. 2008;372:1240-1250.

70. Nauck MA, Sauerwald A, Ritzel R, Holst JJ, Schmiegel W. Influence of glucagon-like peptide 1 on fasting glycemia in type 2 diabetic patients treated with insulin after sulfonylurea secondary failure. Diabetes Care. 1998;21:1925-1931.

71. Nauck MA, Wollschläger D, Werner J, et al. Effects of subcutaneous glucagon-like peptide 1 (GLP-1 [7-36 amide]) in patients with NIDDM. Diabetologia. 1996;39:1546-1553.

72. Larsen J, Hylleberg B, Ng K, Damsbo P. Glucagon-like peptide-1 infusion must be maintained for $24 \mathrm{~h}$ /day to obtain acceptable glycemia in type 2 diabetic patients who are poorly controlled on sulphonylurea treatment. Diabetes Care. 2001;24:1416-1421.

73. Klonoff DC, Buse JB, Nielsen LL, et al. Exenatide effects on diabetes, obesity, cardiovascular risk factors and hepatic biomarkers in patients with type 2 diabetes treated for at least 3 years. Curr Med Res Opin. 2008;24:275-286.

74. Jonker DM, Watson E, Toft AD,Kristensen P, Knudsen LB, Ingwersen SH. Pharmacokinetic modelling of the once-daily human glucagon.like peptide-1 analogue, liraglutide, in healthy volunteers and comparison to exenatide. Diabetologia. 2007;50 Suppl 1:S351 (abstract).

75. Herman GA, Bergman A, Stevens C, et al. Effect of single oral doses of sitagliptin, a dipeptidyl peptidase- 4 inhibitor, on incretin and plasma glucose levels after an oral glucose tolerance test in patients with type 2 diabetes. J Clin Endocrinol Metab. 2006;91:4612-4619.
76. Hjollund KR, Hughes TE, Deacon CF, Holst JJ. The dipeptidyl peptidase-4 inhibitor vildagliptin increases portal concentrations of active GLP-1 to a greater extent than the peripheral concentrations. Diabetes. 2008;57 (Suppl 1):A411 (abstract).

77. Holst JJ, Deacon CF. Glucagon-like peptide-1 mediates the therapeutic actions of DPP-IV inhibitors. Diabetologia. 2005;48:612-615.

78. Göke B, Hershon K, Kerr D, et al. Efficacy and safety of vildagliptin monotherapy during 2-year treatment of drug-naïve patients with type 2 diabetes: comparison with metformin. Horm Metab Res. 2008;40: 892-895.

79. Pratley RE, Schweizer A, Rosenstock J, et al. Robust improvements in fasting and prandial measures of beta-cell function with vildagliptin in drug-naïve patients: analysis of pooled vildagliptin monotherapy database. Diabetes Obes Metab. 2008;10:931-938.

80. Xu L, Man CD, Charbonnel B, et al. Effect of sitagliptin, a dipeptidyl peptidase-4 inhibitor, on beta-cell function in patients with type 2 diabetes: a model-based approach. Diabetes Obes Metab. 2008;10: 1212-1220.

81. Ahren B, Schweizer A, dejager S, Dunning BE, Persson M, Foley JE. Vildagliptin improves alpha cell glucose sensing in patients with type 2 diabetes. Diabetologia. 2008;51 Suppl 1:S36 (abstract).

82. DeFronzo RA, Okerson T, Viswanathan P, Guan X, Holcombe JH, MacConell L. Effects of exenatide versus sitagliptin on postprandial glucose, insulin and glucagon secretion, gastric emptying, and caloric intake: a randomized, cross-over study. Curr Med Res Opin. 2008;24:2943-2952.

83. Novo Nordisk [website]. Liraglutide press release, 16 June 2008 [accessed 3rd December 2008]. Available from: http://www.novonordisk. com/science/Pipeline/liraglutide-press-releases.asp 
